Revista Internacional Educon | ISSN 2675-672

Volume 2, n. 1, e20011026, jan./mar. 2021

bttps://doi.org/ 10.47764/e20011026

Estratégia de Diversificação Horizontal: um Estudo em Empresas Gráficas da Região Metropolitana de Campinas-SP

Horizontal Diversification Strategy: a Study in Graphic Companies in the Metropolitan Region of Campinas-SP

Estrategia de Diversificación Horizontal: un Estudio en Empresas Gráficas en la Región Metropolitana de Campinas-SP

MARCOS LEITE DE ARAUJO

Universidade Metodista de Piracicaba (UNIMEP)

RESUMO: Este artigo teve como objetivo identificar como a diversificação horizontal dos processos de impressão é utilizada em empresas gráficas da Região Metropolitana de Campinas-SP. O estudo empírico considerou uma amostra de quatro empresas gráficas pertencentes a esta região. O método utilizado é considerado exploratório e qualitativo, em um estudo múltiplo de casos. Os dados coletados foram tratados e analisados com o auxílio do software de análise de dados qualitativos Atlas.ti 8. Segundo os achados do estudo, a principal razãa para a diversificação dos processos de impressão foi para compensar a queda na produção do sistema tradicional. Entre as principais dificuldades encontradas pelas empresas estão a falta de recursos financeiros, conbecimento e mão de obra qualificada. Considera-se que a principal descoberta dessa pesquisa foi que grande parte das empresas gráficas que diversificam utilizam a terceirização. Dessa forma, compreende-se, que o mercado de impressão digital, laser e plotter, estão em expansão.

PROCESSOS DE IMPRESSÃO. INDÚSTRIA GRÁFICA. ESTRATÉGIA DE DIVERSIFICAÇÃO HORIZONTAL.

\begin{abstract}
This article aimed to identify how the horizontal diversification of printing processes is used in printing companies in the Metropolitan Region of Campinas-SP. The empirical study considered a sample of fourprinting companies belonging to this region. The method used is considered exploratory and qualitative, in a multiple case study. The data collected were treated and analyzed with the aid of qualitative data analysis software Atlas.ti 8. The main reason for the diversification of printing processes, found in the research was to compensate for the drop in production of the traditional system. Among the main difficulties encountered by companies is the lack of financial resources, knowledge and qualified labor. It is considered that the main discovery of this research is that a large part of the graphic companies that diversify use outsourcing. Thus, it is understood that the digital printing, laser and plotter market are in expanding.
PRINTING
PROCESSES.
GRAPHIC
INDUSTRY.
HORIZONTAL

\section{DIVERSIFICATION STRATEGY.}

O autor cedem à Revista Internacional Educon os direitos de primeira publicação do presente artigo. Aplicam-se os termos de uma licença Creative Commons Atribuição 4.0 Internacional (CC BY 4.0), que permite o uso irrestrito, a distribuição e a reprodução em qualquer meio desde que a publicação original seja corretamente citada. 


\begin{abstract}
RESUMEN: Este artículo tuvo como objetivo identificar cómo se utiliza la diversificación horizontal de los procesos de impresión en las empresas de impresión de la Región Metropolitana de Campinas-SP. El estudio empirico consideró una muestra de cuatro imprentas pertenecientes a esta región. El método utilizado se considera exploratorio y cualitativo, en un estudio de caso múltiple. Los datos recopilados fueron tratados y analizados con la ayuda del software de análisis de datos cualitativos Atlas.ti 8. La principal razón para la diversificación de los procesos de impresión, encontrada en la investigación, fue compensar la caída en la producción del sistema tradicional. Entre las principales dificultades que enfrentan las empresas se encuentra la falta de recursos económicos, conocimientos y mano de obra calificada. Se considera que el principal descubrimiento de esta investigación es que gran parte de las empresas gráficas que diversifican utilizan la subcontratación. Así, se entiende que el mercado de la impresión digital, láser y plóter está en expansión.

PROCESOS DE IMPRESIÓN. INDUSTRIA GRÁFICA. ESTRATEGIA DE DIVERSIFICACIÓN HORIZONTAL
\end{abstract}

\title{
Introdução
}

Atualmente, as enormes e rápidas mudanças, em diferentes aspectos sociais e econômicos, levam as empresas a buscarem novas possibilidades de crescimento, desenvolvimento ou manutenção de sua posição no mercado (Adobor, 2019). Diante desse cenário, o processo de pensar de maneira diferente e considerar outras possibilidades assume importante papel para aquisição de diferencial competitivo (Lembe, 2018).

De acordo com Dal et al. (2017) e Pessoa (2010), uma das estratégias que apresenta maior efetividade competitiva é a diversificação de produtos e/ou serviços.

A discussão teórica em torno dos aspectos da diversificação se intensificou principalmente após a obra de Penrose (1959). Em sua obra, a autora aborda as características comuns entre organizações, cujos crescimentos estão associados à expansão da diversificação. De acordo com Vallandro (2016), o tema diversificação foi amplamente estudado por diferentes áreas do conhecimento nas últimas décadas como uma temática central em pesquisas de administração estratégica.

Segundo Kretzer (2015), a indústria de transformação foi uma das atividades econômicas que mais diversificaram suas atividades, e a indústria gráfica, pertencente a este setor, exibiu os níveis mais elevados de diversificação.

De acordo com Costa (2018), esse resultado se deve, em grande medida, às mudanças tecnológicas no setor e condições de grande competitividade. Ainda de acordo com Costa (2018), as empresas gráficas diversificam seus modelos de impressão em contraponto ao supracitado, formando, assim, um portfólio de produtos e serviços diversificados.

Para Smith \& Coy (2018), a estratégia de diversificação pode melhorar o desempenho competitivo quando esta contém subsídios necessários para respaldá-la. Com o mesmo entendimento, Freire (2019) argumenta que através da diversificação do mix de produtos e/ou serviços, a empresa proporciona, no mesmo estabelecimento, produtos e serviços capazes de atender uma gama maior de clientes.

Nesse sentido, a diversificação em empresas gráficas é um aspecto básico, mas não compreendido amplamente nos estudos dessas empresas (Caspary, 2016; Justo, 2015; Kretzer, 2015; Vieira; Araújo, 2015).

Assim, cumpre-se investigar se as empresas gráficas da Região Metropolitana de Campinas-SP, que utilizam estratégias de diversificação, melhoram o desempenho competitivo. Dessa forma, este estudo se propõe a responder à seguinte pergunta: como a diversificação horizontal dos processos de impressão é utilizada em empresas gráficas da Região Metropolitana de Campinas-SP?

Nesse sentido, este estudo justifica-se por avaliar a implementação da estratégia de diversificação horizontal, visando apresentar as dificuldades encontradas e os resultados da estratégia de diversificação horizontal em cada empresa pesquisada. 


\section{Diversificação}

\subsection{Estratégia de Diversificação}

A estratégia de diversificação é abordada de diferentes formas na literatura. De acordo com Teece (1982) e Mintzberg et al. (2000), a diversificação é proveniente da natureza e da evolução das competências organizacionais, a qual envolve os novos conhecimentos e habilidades intermediados por forças endógenas e exógenas que são formadas durante o processo de aprendizagem.

Para Porter (1985), a diversificação acontece por um conjunto de forças externas (demanda, tendências sociais, economia, clientela, inovações, entre outras) que são incontroláveis e influenciam as decisões organizacionais.

Para Ansoff (1971), a diversificação acontece por percepções mercadológicas sobre o nível de maturidade dos produtos, ao qual permite-se a criação de novos produtos e mercados. Nesse sentido, Silva (2018) acrescenta que a constante avaliação de produtos e mercados propicia novas oportunidades. Ansoff (1971) definiu quatro formas de se diversificar:

- Diversificação Horizontal - desenvolvimento de novos produtos ou serviços que atendam os mesmos grupos de clientes;

- Diversificação Vertical - a empresa avança ou retrocede em estágios da sua cadeia produtiva, na produção de sua própria matéria prima ou na distribuição de produtos ou serviços;

- Diversificação concêntrica - utiliza a expertise, o potencial produtivo e as tecnologias já instaladas para produção de novos produtos ou serviços, e;

- Diversificação Heterogénea - que não tem relação com os produtos e serviços existentes, tampouco com os clientes e o mercado.

Dentre essas quatro formas de diversificação definidas por Ansoff (1971), a diversificação horizontal é a que mais se assemelha ao conceito de Penrose (1959) para diversificação tratada nessa pesquisa.

Penrose (1959) define a diversificação sempre que a firma, sem deixar completamente sua antiga linha de produtos, inicia a fabricação de novos produtos, ou produtos intermediários, mas que são substancialmente diferentes dos produtos que ela já produzia, impactando em diferença significativa nos processos produtivos e de distribuição da firma.

Freire (2019) e Kretzer (2015) apontam que o sucesso em diversificar está relacionado com a criação ou a exploração de mercados ineficientes. Para Smith \& Coy (2018), a decisão de diversificar é uma das decisões mais difíceis enfrentadas pelas empresas. Porter (1996) argumenta ainda que antes de se diversificar é fundamental que a empresa identifique quais são suas vantagens competitivas. Isso se deve pela natureza arriscada dessa estratégia.

De acordo com Ansoff (1971), a estratégia de diversificação horizontal se difere das demais pelas manobras internas do ambiente econômico da empresa que diversifica. Não se observam, normalmente, flexibilidade e tão pouco contribuição para aumento da estabilidade da empresa.

O ponto forte encontrado neste tipo de diversificação é a sinergia existente entre os demais setores, principalmente de Marketing, visto que a empresa continua a vender pelos canais já estabelecidos.

Para Ramanujam \& Varadarajan (1989), a organização pode adentrar em novos mercados por meio de aquisições, alianças ou fusões, ou mesmo a combinação destas estratégias. Entretanto, a união de duas ou mais empresas em torno de um resultado pode gerar, inicialmente, um choque cultural que, quando mal administrado, tende a fracassar (Freire, 2019).

Dessa forma, para que as empresas encontrem sinergia, os gestores devem compreender as diferenças culturais para manter um clima organizacional positivo (Ramanujam \& Varadarajan, 1989). 


\subsection{Motivadores para Diversificar}

Freire (2019) aponta que as empresas adotam a diversificação com o intuito de maximizar seu retorno financeiro. Grzebieluckas et al. (2013) e Lembe (2018) acreditam que a estratégia de diversificação é influenciada pelo baixo crescimento e desempenho limitado.

Essa afirmação é corroborada por Vallandro (2016), que demonstra evidências de que as empresas são motivadas a diversificar como forma de potencializar seu crescimento.

Historicamente, empresas escolhem diversificar para evitar restrições de mercado, ou porque possuem vantagens, tais como recursos humanos, equipamentos, habilidades técnicas entre outras (Saracco et al., 2015; Dal et al., 2017; Freire, 2019).

De acordo com Penrose (1979), a diversificação é utilizada, geralmente, como uma solução para se amenizar as desfavoráveis condições da demanda. Para Smith \& Coy (2018), a demanda de alguns produtos é instável, com períodos de sazonalidades inconsistentes. Além disso, a empresa pode ter a demanda prejudicada e retrair-se severamente em função das sucessivas e, por vezes, bem-sucedidas incursões de concorrentes (Silva et al., 2017).

Nesta linha de raciocínio, Penrose (1995, p.180) defende que as firmas eficientes e bem-sucedidas são diversificadas, enquanto "as firmas especializadas são vulneráveis". Para a autora, as empresas que são especializadas sofrem constantes ameaças, primeiro pela concorrência e, segundo pelas rápidas mudanças do mercado.

Por outro lado, durante o tempo, algumas organizações adquirem competências e podem expandir suas atividades (Soltanizadeh et al., 2016). Para Mintzberg et al. (2000), tais oportunidades surgem por fatores internos ou externos à organização. Nesse sentido, a organização pode optar por aplicar ou renovar suas competências, dando origem a novos processos capazes de atender mercados distintos.

Algumas empresas estabelecidas, em busca de crescimento, aproveitam-se de falhas no mercado para inserir novos produtos ou serviços (Martins, 2011). Esse tipo de estratégia foi mencionado por Rumelt (1982), descrevendo esse tipo de diversificação como competências distintivas que podem ser usadas pela empresa para explorar as falhas de mercado.

De acordo com Rumelt (1982), essa estratégia de diversificação produz e vende para mercados que não têm interação com aqueles outros produtos da empresa. Nesse caso, segundo o autor, a ausência de interação entre os mercados força a estratégia a priorizar a economia de fatores produtivos e a eficiência organizacional, pois é observado nessa estratégia o baixo compartilhamento de recursos e outras formas de aproveitamento produtivo que sejam comuns (Rumelt, 1982).

Entretanto, Lembe (2018) alerta que, geralmente, as informações não são verdadeiramente confiáveis a fim de permitir uma aferição concludente entre diversificação e expansão, existindo, geralmente mais informações sobre expansão do que diversificação.

Grzebieluckas et al. (2013) destacam três benefícios potenciais com a diversificação horizontal e suas consequências para o aumento da vantagem competitiva: aumento e otimização dos demais setores produtivos, com maior sinergia no uso de recursos; maior oportunidade de estabelecer contato e alinhamento com empresas de outros mercados, e, como consequência, obter confiança tendo em vista à redução dos efeitos das forças de mercado e; a possibilidade de se obter os benefícios de mercados estruturados, com a interação e relacionamentos entre os nichos de mercado dentro da mesma indústria.

Ramanujam \& Varadarajan (1989) afirmam que a tecnologia faz parte de um conjunto de recursos que constituem a base para a formulação da estratégia para diversificar. Freire (2019) e Martins (2011) sugerem que os gestores verifiquem se os recursos viabilizarão o processo de diversificação, trazendo o retorno esperado, e se de fato os resultados são interessantes para a organização.

Estudos que relacionam a estratégia de diversificação e o desempenho competitivo, em sua maioria, são analisados sob a perspectiva dos recursos (Martins, 2011). Nesse sentido, a diversificação está diretamente relacionada ao grau de recursos e capacidades, em que as empresas lançam seus produtos e serviços com retorno sobre o investimento (Penrose, 1959; Teece, 1982). 


\section{Metodologia}

Para captar de forma aprofundada a natureza do objeto em questão, essa pesquisa apresenta-se como qualitativa, por ser o meio mais indicado para estudar áreas do saber ainda em construção (Flick, 2009).

A estratégia utilizada para essa pesquisa foi o estudo de casos múltiplos que, seguindo as recomendações de Yin (2015), além dar maior robustez à pesquisa, possibilita a investigação do mesmo fenômeno em diferentes ambientes.

Ademais, buscou-se a triangulação de evidências levantadas nos diferentes casos estudados, por meio de entrevistas semiestruturadas e observações, confrontando-os com o referencial utilizado nesse estudo.

Nessa pesquisa as observações foram feitas no mesmo dia das entrevistas. Os elementos que foram objeto de observação do pesquisador referem-se aos processos de impressão que são utilizados nas empresas gráficas pesquisadas.

\subsection{Unidades de Análise e Amostra}

A escolha das gráficas teve um caráter não probabilístico e foram definidas pela facilidade e/ou disponibilidade de acesso às empresas. A amostra pesquisada corresponde a quatro gráficas pertencentes a Região Metropolitana de Campinas-SP.

O total de empresas gráficas desta região aproxima-se das 797 gráficas, sendo este o número divulgado para ano de 2015, segundo o relatório da Associação Brasileira da Indústria Gráfica (Abigraf, 2016). As empresas e os dirigentes preferiram manter sigilo de suas identidades. Dessa forma, utilizou-se letras e números para identificá-los.

As empresas serão representadas nesse trabalho, portanto, como G1, G2, G3 e G4. Os entrevistados serão apresentados como diretores ou gerentes.

As unidades de análise, todas localizadas na Região Metropolitana de Campinas-SP, declararam diversificar seus processos de impressão. O quadro 1 fornece uma visão da amostra estudada.

\begin{tabular}{|l|l|l|l|l|l|l|}
\hline Empresa & Entrevistado & Cidade & Fundação & $\begin{array}{c}\text { Início } \\
\text { Diversificação }\end{array}$ & $\begin{array}{l}\text { Quant. } \\
\text { Funcionários }\end{array}$ & $\begin{array}{l}\text { Área } \\
\text { Ocupada }\end{array}$ \\
\hline G1 & Gerente & $\begin{array}{l}\text { Indaiatuba } \\
\text {-SP }\end{array}$ & 1988 & 2018 & 14 & $600 \mathrm{~m} 2$ \\
\hline G2 & Diretor & $\begin{array}{l}\text { Valinhos- } \\
\text { SP }\end{array}$ & 1996 & 2014 & 15 & $360 \mathrm{~m} 2$ \\
\hline G3 & Gerente & $\begin{array}{l}\text { Campinas- } \\
\text { SP }\end{array}$ & 1994 & 2012 & 18 & $600 \mathrm{~m} 2$ \\
\hline G4 & Diretor & $\begin{array}{l}\text { Hortolândi } \\
\text { a-SP }\end{array}$ & 1982 & 2014 & 9 & $300 \mathrm{~m} 2$ \\
\hline
\end{tabular}

Quadro 1: Composição da Amostra Estudada

Fonte: Elaborado Pelo Autor 
As quatro entrevistas foram realizadas em suas respectivas sedes, no período de dezembro de 2019 a fevereiro de 2020, dando respaldo ao trabalho e ajudando no entendimento mais aprofundado da realidade do universo gráfico da Região Metropolitana de Campinas (SP).

\subsection{Análise dos Dados}

Os dados obtidos, por intermédio das entrevistas em profundidade, foram analisados com a utilização da técnica de análise de conteúdo de Bardin (2011).

Para o tratamento dos dados foram utilizados recursos do software Atlas.ti 8.0, associado e orientado segundo à análise temática de Bardin (2016), como recomendado por Forte et al. (2017). Os procedimentos para tratamento dos dados foram pré-análise, transcrição literal das entrevistas e subsequente interpretação.

Cabe mencionar que a análise de conteúdo permite a utilização de diversas estratégias de análise em seu desenvolvimento (Bardin, 2016). Dessa maneira, a procura por critérios de confiabilidade e validade se constituem num caminho para superação das limitações, que são inerentes à própria análise de conteúdo.

\section{Apresentação e Análise dos Dados}

Como forma de facilitar a compreensão do trabalho, inicialmente faz-se uma breve apresentação dos entrevistados, para posteriormente apresentar os dados coletados junto às quatro empresas da amostra de pesquisa. A intenção é, portanto, realizar uma descrição clara e detalhista para esclarecer como foi o processo de diversificação de cada empresa gráfica.

\subsection{Apresentação dos Dados das Unidades de Análise}

\subsubsection{Empresa G1}

O respondente da empresa G1 foi o gerente administrativo, responsável pela gestão da empresa. O profissional atua na empresa há 8 anos nessa mesma função, tendo atuado como gerente em outra empresa gráfica por 12 anos e, portanto, apto a responder aos questionamentos do pesquisador. De acordo com o gerente, o principal processo de impressão é o offset, mas a empresa utiliza hoje os processos digital laser e plotter.

A gráfica percebeu que durante o tempo a demanda de produtos impressos pelo processo de impressão offset caíram, e que os clientes da gráfica procuravam por outros tipos de impressão que a gráfica ainda não possuía. Daí é que surgiu o interesse em diversificar, mas foi uma estratégia reativa, foi por causa da demanda mesmo (Gerente G1).

Durante a entrevista, o gerente da empresa G1 revelou que o principal motivo da diversificação foi para aumentar a demanda e melhorar o faturamento. Segundo o entrevistado, a empresa G1 já estudava essa possibilidade e que, se não fosse dessa forma - a formação de um grupo — cedo ou tarde a empresa teria tomado essa decisão.

(...) deixando claro que hoje nós oferecemos outros tipos de impressão (digital e plotter) por conta da fusão que fizemos há pouco mais de um ano com outra empresa com experiência nesse segmento. Essa fusão deu origem a um grupo formado por duas empresas, a nossa que trabalha 
há 22 anos com o processo offset e a outra que trabalha com os outros processos (digital e plotter) há 6 anos (Gerente G1).

O entrevistado disse que o grupo, formado pelas duas empresas, ainda está em fase de adaptação e que os conhecimentos ainda estão sendo compartilhados. A empresa G1 tem setores bem distribuídos. Segundo o profissional, o que eles fizeram foi adaptar os equipamentos vindos da outra empresa, que não são muitos, na planta da empresa. Ele disse que na prática retiraram alguns equipamentos que eram obsoletos para acomodar os que vieram com a outra empresa.

Hoje a empresa oferece impressos offset, laser e plotter. Segundo o profissional da empresa G1, não foi preciso treinamento uma vez que a empresa, que agora faz parte do grupo, possui mão de obra experiente e equipamentos, assim como o conhecimento e habilidades. Para cada processo a empresa utiliza um tipo de acabamento e, segundo o entrevistado, raríssimas vezes os processos usam os mesmos equipamentos de acabamento ou de pré-impressão.

Quando perguntado quais foram os desafios encontrados, o respondente disse que houve um choque de cultura com a união de duas empresas.

O primeiro ponto foi o choque de cultura das duas empresas. Quando nós recebemos os novos colaboradores percebemos que eles eram muito jovens, que teoricamente tem acesso a milhões de outras informações muito rápido. O segundo acredito que foi dentro do sistema, porque nós temos um sistema de gestão que não tem como parametrizar nesse momento, os orçamentos que estão entrando, enfim...os digitais e plotter. O terceiro ponto, que eu vejo que não é o mais grave seria a parte de horário, que ainda não conseguimos ajustar, ou entrar em um acordo. Porque até então a outra empresa que está migrando para nossa tem um outro processo, que envolve a cultura também, enfim. Mas isso não diz respeito a engajamento, não é a falta de empenho, pelo contrário. Mas é uma questão importante que temos que resolver (Gerente G1).

Sobre os resultados da diversificação, o entrevistado disse que ainda é cedo para uma afirmação, visto que o grupo foi formado há pouco mais de um ano. No entanto, ele acrescenta que antes os outros processos eram terceirizados e hoje a empresa presta serviços de impressão digital, laser e plotter à outras gráficas.

É muito difícil apontar um diferencial, mas visionando eu acredito sim que a diversificação será um diferencial para gráfica. Não consigo mensurar isso agora, mas eu vejo como vantagem pelo fato do cliente que quer offset ele tem também a opção do digital ou plotter, da mesma forma o cliente que vem atrás do digital ou plotter tem a opção do offset, vou dizer que abrimos o leque. Mas assim, eu não consigo enxergar claramente isso para apontar claramente isso agora (Gerente G1).

\subsubsection{Empresa G2}

Quem representou a empresa G2 durante a entrevista foi o gerente de produção, que atua nessa função desde 2016, mas trabalha na empresa desde sua fundação em 2009. O entrevistado não teve outras experiências profissionais na indústria gráfica, mas mostrou-se conhecedor da empresa e do segmento gráfico, com respostas seguras e objetivas quando questionado.

Quando perguntado quais foram os motivos para diversificação, o Gerente da empresa G2 disse que foi uma necessidade, pois existia a demanda por impressos digitais e precisaram se adaptar, já que a opção de parcerias com outras empresas para produção não atendia a necessidade.

(...) surgiu a partir da identificação de novos produtos que nossos clientes estavam desenvolvendo. Para atendê-los, inicialmente tivemos que buscar parcerias. Só depois, quando 
tivemos alguns problemas com os prazos de entrega, é que alugamos nossa primeira impressora digital (Gerente G2).

De acordo com o gerente da empresa G2 a opção de diversificar foi para atender a demanda e também pela necessidade de manter o faturamento.

A impressão offset sozinha já não dá conta, a produção tem caído muito nos últimos anos. Quando começamos com a gráfica, o sistema digital ainda era novidade, poucas gráficas se aventuravam nesse sistema, mesmo porque existia muita demanda pela impressão offset. $\mathrm{O}$ sistema digital hoje faz parte da evolução do setor. Antes havia antes um tipo de conhecimento sobre como funcionava o mercado de impressão digital, nós sabíamos que era diferente, outro processo, enfim, mas quando começamos a produzir aqui é que percebemos seu potencial. É um processo que você precisa estar em constante evolução, praticamente a cada dia surge um equipamento novo. Vou dizer que hoje estamos mais tecnológicos (Gerente G2).

Quando perguntado como surgiu o interesse em diversificar, o respondente disse que surgiu a partir da identificação do interesse de seus clientes por novos produtos. Para atendê-los, o gerente disse que inicialmente buscaram parcerias. Só depois, quando tiveram alguns problemas como prazos não cumpridos pelos parceiros é que adquiriram a primeira impressora digital, mas ainda utiliza parcerias para alguns trabalhos, pois sua impressora não comporta todos os tipos de papéis.

Segundo o profissional, seus diferenciais são boa qualidade e um bom serviço de pós-venda. As atividades que tiverem maiores mudanças, de acordo com o respondente, foram marketing e gestão de pessoas. Explica o Gerente da empresa G2:

A impressora foi locada por ser pra nós a melhor opção, marketing porque começamos a divulgar mais nas plataformas digitais, e gestão de pessoas porque foi preciso contratar e realocar algumas pessoas (Gerente G2).

O gerente da empresa G2 disse que utiliza quase os mesmos equipamentos de pré-impressão e acabamento para a impressão offset e o digital laser. Quanto às mudanças, o respondente disse que foram poucas porque os equipamentos ocupam pouco espaço físico. O gerente da empresa G2 ressalta algumas dificuldades que teve para inserir novos processos de impressão:

A maior dificuldade com certeza foi conseguir a máquina. Na época não tínhamos capacidade financeira de investimento, e essas máquinas são bem caras, por isso alugamos. Outra dificuldade foi encontrar mão de obra. Tentamos realocar algumas pessoas, mas depois tivemos que encontrar quem já tinha experiência. Tivemos um pouco de dificuldade também pra divulgar, aí começamos a utilizar as plataformas digitais (Gerente G2).

A empresa optou em diversificar com o digital a laser por conta de sua capacidade financeira pois, segundo o respondente, nesse processo não são necessários grandes investimentos.

\subsubsection{Empresa G3}

O entrevistado foi o sócio diretor, filho do fundador da empresa, que desde muito jovem acompanha o crescimento da empresa ao lado de seu pai, assumindo em 2014 o cargo de diretor comercial. O entrevistado declarou conhecer a empresa e o setor, principalmente a área comercial. Quando perguntado o que motivou a empresa a diversificar, o diretor respondeu que acha que o futuro da indústria gráfica será a impressão digital. 
O entrevistado disse que o primeiro equipamento digital, comprado em 2012, não atendia a sua demanda. A maioria de seus trabalhos de impressão digital era terceirizado.

\begin{abstract}
Quando começamos o sistema digital ainda era novidade, poucas gráficas trabalhavam com isso. Aqui na gráfica, até 2018 mais ou menos, nosso foco era offset. Nós fomos bem devagar com o digital, fomos bastante cautelosos, várias gráficas investiram errado e perderam dinheiro. Compramos a digital em 2012 para fazer coisas pequenas, mas ela não atendia, dava muito problema e a qualidade não era boa. Tanto é que a impressora digital antiga ficou quebrada um tempo e nessa época nós terceirizamos os digitais. A segunda nós só compramos depois de muita pesquisa (Diretor G3).
\end{abstract}

O diretor da empresa G3 disse que agora a empresa possui duas impressoras digitais, compradas em 2017 e 2018 que atendem às suas necessidades, mas 80\% do faturamento ainda vem do offset. Quando questionado se precisou mudar alguma na empresa, o respondente disse que no começo não fizeram muitas mudanças e usaram os mesmos funcionários.

(...) os processos são bem diferentes, tanto é que quando compramos a impressora grande, em 2017, contratamos mais dois funcionários que já conheciam a máquina e as atividades de produção. Aprendemos que não dá certo transferir um impressor do offset para o digital, são bem diferentes. Hoje são 4 funcionários exclusivos para o digital (Diretor G3).

A empresa G3 disse que compartilha muito pouco os demais setores da empresa entre os processos offset e o digital. No digital os quatro funcionários trabalham na impressão, pré-impressão e acabamento. Diferente do offset onde cada funcionário tem uma função. Algumas vezes o digital utiliza a mesma guilhotina, picotadeira ou a furadeira, mas a digital tem ferramentas diferentes.

Perguntado quais tipos de conhecimentos a diversificação trouxe, o diretor da empresa G3 disse que a diversificação trouxe mais conhecimento do mercado. Acrescentou que há um tempo perceberam que as gráficas estão passando por um processo evolutivo e estão tentando acompanhar esse processo. De acordo com o entrevistado, a maioria de seus concorrentes usa os mesmos equipamentos que a empresa G3. Seu diferencial é o compromisso que tem com seus clientes e, graças a isso, conseguem manter seus clientes.

Quanto ao mercado atendido, o entrevistado disse que no geral oferecem para o mesmo mercado. No digital, fazem alguns trabalhos para pessoa física, e que isso era mais raro, mas no geral é o mesmo mercado. Complementou dizendo que melhorou o faturamento da empresa.

(...) a margem do digital é bem maior do que o offset. Apesar da grande maioria dos impressos ainda ser offset, o digital vem aumentando. Acho que o futuro é o digital, não temos grandes expectativas no processo offset (Diretor G3).

Com relação à estratégia de diversificação, se o diretor a considera um diferencial competitivo, o entrevistado respondeu que não considera assim. Ele disse que quase todas as gráficas pequenas, e até às médias já usam essa estratégia, e concluiu dizendo: "quem não diversificar vai ficar para trás". Quanto aos benefícios da diversificação, o respondente disse que com a diversificação ele pode continuar a prestar serviços gráficos.

\title{
4.1.4 Empresa $G 4$
}

O entrevistado é um dos diretores que trabalha na empresa há 12 anos. Sua principal atividade na empresa é de orçamentista, porém o entrevistado demonstrou conhecimento do assunto pesquisado quando indagado pelo pesquisador sobre questões pertinentes desta pesquisa. 
O diretor da empresa G4 disse que o caminho para o desenvolvimento de novos produtos, inicialmente, aconteceu por meio de parcerias para gerar uma demanda que justificasse a compra do equipamento. A demanda esperada, segundo o respondente, aumentou aos poucos e levou cerca de seis meses. Após esse período é que a empresa contratou um funcionário. Sobre as dificuldades, o respondente disse:

(...) acho que foi adquirir conhecimento de novos materiais que não trabalhávamos antes, sair da zona de conforto como dizem né!? Também não foi fácil encontrar alguém bom pra trabalhar (Diretor G4).

O respondente disse que mesmo após adquirir a primeira impressora digital, continuou a utilizar parcerias para impressão de alguns impressos digitais. Somente em 2016, após comprarem a segunda impressora digital e um plotter, se tornaram autossuficientes no sistema de impressão. De acordo com o diretor, atualmente a empresa presta serviços de impressão à outras gráficas.

(...) nós já fazíamos alguns trabalhos digitais com parceiros nossos. Na época tinha muito trabalho pra offset, quando aparecia alguma coisa digital a gente terceirizava. Só depois começou a aumentar e vimos que era a hora de comprar uma digital. O mercado gráfico já vem diminuindo as quantidades, já não tem pedidos de 100.000, 200.000 panfletos mais, então foi preciso a gráfica se adaptar pra atender nossos clientes (Diretor G4).

O diretor disse que os diferenciais da empresa são qualidade, conhecimento e pós-venda. Sobre alguma dificuldade em diversificar, o respondente argumentou que foram resolvidas com a contratação de um funcionário com experiência. $\mathrm{O}$ entrevistado disse também que as mudanças na empresa foram mínimas, já que o espaço que as impressoras utilizam estava vazio há algum tempo.

(...) diferente do offset, esses equipamentos precisam de pouco espaço. Aqui as duas digitais e mais o plotter ficam numa sala de 24 metros quadrados. Essa sala a gente usava pra guardar sobras de papel e outras coisas. Foi só preparar ela com instalação elétrica e colocar ar condicionado (Diretor G4).

De acordo com o entrevistado, o grande retorno que a empresa teve foi a substituição da demanda do processo offset para os sistemas digitais:

Hoje o digital é essencial, tanto pra manutenção do cliente, quanto pra conseguir outros. A diminuição do offset foi suprida pela impressão digital e em outros materiais com o plotter (Diretor G4).

\subsection{Análise dos Resultados}

Nessa seção, são analisadas as estratégias utilizadas pelas quatro empresas estudadas com o intuito de encontrar semelhanças e/ou diferenças nos aspectos relacionados à estratégia de diversificação horizontal nos processos de impressão.

Dessa maneira, fez-se uma análise comparativa procurando demonstrar os principais motivos e dificuldades no uso da estratégia de diversificação relatadas pelos dirigentes nas entrevistas.

Para tal, as entrevistas transcritas foram inseridas no software de análise de dados qualitativos (Atlas.ti 8.0), e a partir da análise de todo o conjunto de dados obtido, este foi submetido à codificação temática para a identificação de temas e construtos-chave (Forte et al., 2017).

A possibilidade de codificação foi mantida aberta para possibilidade do surgimento de novos temas. 
Assim, a partir da análise conjunta dos códigos criados previamente, juntamente com os códigos que emergiram da análise dos dados e com a rede criada entre os códigos, foram identificados os temas a serem explorados nessa análise intercaso:

- Motivadores e dificuldades para diversificar;

- Diversificação e tipos de serviços/produtos, e;

- Impactos da estratégia de diversificação.

Com os dados organizados nesses temas, elaborou-se a análise crítica da estratégia de diversificação dos processos de impressão das empresas pesquisadas.

\subsubsection{Motivadores e dificuldades para diversificar}

De acordo com o apresentado no referencial teórico, a diversificação pode ser utilizada para diferentes finalidades como: uma solução para se amenizar as desfavoráveis condições da demanda (Penrose, 1979); adquirem competências e expandir suas atividades (Soltanizadeh et al., 2016); potencializar o crescimento (Freire, 2019); por forças internas e/ou externas (Porter, 1996); oportunidades de mercado (Ansoff, 1971); aumentar o retorno financeiro (Vallandro, 2016); por conta da concorrência (Silva et al., 2017); conseguir melhor desempenho (Grzebieluckas et al., 2013) e; aumentar a demanda (Smith \& Coy, 2018).

Nas entrevistas, falou-se muito sobre os motivos e as dificuldades da indústria gráfica para diversificar o processo de impressão. O gerente da empresa G2 disse que a empresa precisou diversificar o processo de impressão para manter o faturamento que caía mês a mês com o processo offset "(...) a impressão offset sozinha já não dá conta, a produção tem caído muito nos últimos anos".

Da mesma forma, e com a justificativa da queda na produção, o gerente da empresa G1 relatou que a gráfica diversificou o processo de impressão porque perceberam que seus clientes demandam por outros tipos de impressão.

A análise das respostas indica que há motivações estratégicas, mercadológicas e financeiras nas empresas pesquisadas, de como ampliar a atuação no mercado, atender a demanda de seus clientes e aumentar o faturamento.

O diretor da empresa G4 tocou nesse ponto, como está na transcrição de parte de sua entrevista: "cada vez mais estava difícil depender só de serviços offset. Os custos dos serviços de offset são grandes". O diretor da empresa G3 declarou que $80 \%$ de seu faturamento ainda vem do offset, e as demais empresas também declararam que têm nesse processo sua principal fonte de receita.

A motivação financeira pôde ser vista nas quatro empresas. Embora cada uma tenha diversificado em momentos distintos, todas buscam a possibilidade de aumentar a receita, o que está em linha com os preceitos da literatura (Penrose, 1959; Teece, 1982; Grzebieluckas et al., 2013; Vallandro, 2016; Lembe, 2018).

Sobre as dificuldades no processo de diversificação, dois dirigentes apontaram não encontrar mão de obra especializada, G2 e G4, de Valinhos-SP e Hortolândia-SP respectivamente.

A empresa G1, da cidade de Indaiatuba-SP, não declarou essa dificuldade porque, segundo o entrevistado, foi feita a união com outra empresa que já atuava com os novos processos.

As principais dificuldades, segundo o gerente da empresa G2, foi a compra dos equipamentos e conseguir mão de obra para operação. Esses mesmos desafios também foram relatados pela empresa G4.

Nesse sentido, as entrevistas reforçam as dificuldades que o setor gráfico enfrenta com a queda na demanda de impressos que utilizam o processo de offset relatado por Costa (2018).

As dificuldades apontadas pelo gerente G1 relacionados a gestão organizacional foram tema nos trabalhos de Freire (2019) e Ramanujam \& Varadarajan (1989). Para esses autores, os gestores das 
empresas devem entender com clareza as diferenças culturais para que possam juntos trabalhar em torno de um mesmo objetivo.

O diretor da empresa G4 também disse que não encontrou dificuldades para compra dos equipamentos e tampouco para encontrar colaboradores com experiência, contradizendo o relato da empresa G2. Da mesma forma, a empresa G3 também disse não ter encontrado dificuldades em conseguir mão de obra.

Os procedimentos e as dificuldades da indústria gráfica em diversificar, identificadas nas entrevistas, estão sintetizadas no quadro 2.

\begin{tabular}{|c|c|c|c|}
\hline & & Motivadores & Dificuldades \\
\hline Empresa G1 & $\begin{array}{l}\text { Indaiatuba- } \\
\text { SP }\end{array}$ & $\begin{array}{l}\text { Atender a demanda e aumentar o } \\
\text { faturamento }\end{array}$ & Gestão organizacional \\
\hline Empresa G2 & Valinhos-SP & $\begin{array}{l}\text { Ampliar o mercado e manter o } \\
\text { faturamento }\end{array}$ & $\begin{array}{l}\text { Capacidade financeira; } \\
\text { encontrar mão de obra }\end{array}$ \\
\hline Empresa G3 & Campinas-SP & $\begin{array}{l}\text { Ampliar o mercado e aumentar a } \\
\text { margem de lucro }\end{array}$ & Falta de demanda \\
\hline Empresa G4 & $\begin{array}{l}\text { Hortolândia- } \\
\text { SP }\end{array}$ & $\begin{array}{l}\text { Ampliar o mercado e atender a } \\
\text { demanda }\end{array}$ & \begin{tabular}{lrr} 
Capacidade & \multicolumn{2}{c}{ financeira; } \\
encontrar mão de obra; \\
conhecimento de novos \\
materiais
\end{tabular} \\
\hline
\end{tabular}

Quadro 2: Motivadores e dificuldades das empresas pesquisadas

Fonte: Dados da pesquisa

\subsubsection{Diversificação e tipos de serviços/produtos}

De acordo com Penrose (1959), é natural que as empresas sejam classificadas como monoprodutoras ou multiprodutoras, ou então, diversificadas ou não diversificadas. Nesse sentido, a autora defende que o sentido desses termos depende da definição que se dá ao produto de referência.

Assim, uma firma que produz somente sapatos pode ser definida como não diversificada, enquanto que, para outros propósitos, uma empresa que produza apenas sapatos, mas de vários tipos, poderá ser considerada diversificada.

Devido a essa ambiguidade e à impossibilidade de comparações de classes, não é possível avaliar com precisão o significado da diversificação comparativa entre empresas diversas, e, nesse sentido, a seguinte análise comparativa não se refere a identificar se uma empresa é mais diversificante que outra. Essa compreensão se baseia na afirmação de Penrose (1959).

O quadro 3 consolida o tipo de diversificação e as atividades das empresas pesquisadas.

\begin{tabular}{|l|l|l|}
\cline { 2 - 3 } \multicolumn{1}{|l|}{} & Diversificação & Serviços/Produtos Oferecidos \\
\hline Empresa G1 & $\begin{array}{l}\text { Analógico Offset, } \\
\text { Digital Laser, Digital } \\
\text { Plotter }\end{array}$ & $\begin{array}{l}\text { *Impressos com processo offset em papel entre } 65 \text { e } 350 \text { grs., formatos entre } \\
16 \text { e } 02 \text { impressos a laser em papel e poliéster de } 70 \text { a } 400 \text { grs., entre os } \\
\text { formatos A8 ao A2 *impressos plotter em vinis, adesivos, lonas, papéis, PVC } \\
\text { dentre outros materiais, com largura máxima de 1,80 metros. }\end{array}$ \\
\hline
\end{tabular}




\begin{tabular}{|l|l|l|l|} 
Empresa G2 & $\begin{array}{l}\text { Analógico } \\
\text { Digital Laser }\end{array} \quad$ Offset, & $\begin{array}{l}\text { *Impressos com processo offset em papel entre } 70 \text { e } 400 \text { grs., com formatos } \\
\text { entre 08 e 02 - impressos a laser em papel e poliéster de } 75 \text { a } 300 \text { grs., entre } \\
\text { os formatos A4 ao A3. }\end{array}$ \\
\hline Empresa G3 & $\begin{array}{l}\text { Analógico } \\
\text { Digital Laser }\end{array} \quad$ Offset, & $\begin{array}{l}\text { *Impressos com processo offset em papel entre } 70 \text { e } 350 \text { grs., com formatos } \\
\text { entre 08 e 01 - impressos a laser em papel e poliéster de } 70 \text { a } 400 \text { grs., entre } \\
\text { os formatos A8 ao A2. }\end{array}$ \\
\hline Empresa G4 & $\begin{array}{l}\text { Analógico } \\
\text { Digital Laser, Digital } \\
\text { Plotter }\end{array}$ & $\begin{array}{l}\text { *Impressos com processo offset em papel entre } 70 \text { e } 450 \text { grs., formatos entre } \\
\text { O8 e 02 *impressos a laser em papel e poliéster de } 70 \text { a } 400 \text { grs., entre os } \\
\text { formatos A8 ao A2 *impressos plotter em vinis, adesivos, lonas, papéis, PVC } \\
\text { dentre outros materiais, com largura máxima de 2,30 metros. }\end{array}$ \\
\hline
\end{tabular}

Quadro 3: Diversificação e Tipos de Serviços/Produtos

Fonte: Dados da pesquisa.

\subsubsection{Impactos da estratégia de diversificação horizontal}

De acordo com os dados coletados, a diversificação horizontal nas empresas gráficas da Região Metropolitana de Campinas trouxe resultados positivos para as gráficas pesquisadas. Nesse sentido, Freire (2019) apontou que o sucesso em diversificar pode estar relacionado, em grande medida, com a exploração de mercados em expansão.

Todos os entrevistados disseram-se satisfeitos com os resultados obtidos com a estratégia de diversificação. Conforme demonstra o depoimento da empresa G3: "A margem do digital é bem maior do que o offset. Apesar da grande maioria dos impressos ainda ser offset, o digital vem aumentando". A declaração do diretor da empresa G2 foi esclarecedora, especialmente quando ele diz que a estratégia "nos deu mais conhecimento do mercado".

No entanto, apesar das declarações de melhora nos resultados, tanto produtivos quanto econômicos, nenhum dirigente considerou a diversificação como um diferencial competitivo.

Nota-se que todas as declarações foram tímidas nesse sentido, pois todos os profissionais disseram que os processos podem ser facilmente copiáveis. As declarações de diferencial competitivo, aliadas à estratégia de diversificação, foram voltadas às qualidades individuais de cada empresa, conforme demonstra o quadro 4.

\begin{tabular}{|l|l|}
\hline & Diferencial Competitivo \\
\hline Empresa G1 & Qualidade, localização e atendimento \\
\hline Empresa G2 & Custo benefício justo, qualidade e serviço pós venda \\
\hline Empresa G3 & Compromisso com os clientes e qualidade \\
\hline Empresa G4 & Gráfica enxuta, qualidade e bom atendimento \\
\hline
\end{tabular}

Quadro 4: Diferencial Competitivo das Empresas Pesquisadas

Fonte: Dados da pesquisa 
Nota-se que todas as declarações de diferencial competitivo foram tímidas, todos os profissionais disseram que os processos podem ser facilmente copiáveis. As declarações de diferencial competitivo foram voltadas às qualidades individuais de cada empresa.

Um ponto importante mencionado pelos entrevistados é que os processos digitais ainda têm pouca oferta, mesmo com estudos demonstrando que a maioria das empresas gráfica diversificam (Kretzer, 2015; Vieira \& Araújo, 2015). Outro ponto também importante que se conclui nessa pesquisa é que quatro das quatro empresas prestam serviços de impressão digital a outras gráficas, o que justifica o resultado das pesquisas supracitadas.

Outra revelação, igualmente importante, é que três das quatro empresas começaram a diversificar utilizando o processo digital laser. A exceção é a empresa G1, que iniciou a diversificação já com dois processos devido a união feita com outra empresa. Isso demonstra que o processo de impressão laser tem uma relação de coerência com as atividades de impressão offset.

Conclui-se, portanto, que a diversificação horizontal trouxe resultados positivos nas empresas pesquisadas, e podem indicar uma tendência para as empresas desse setor, o que necessitaria ser melhor estudada.

\section{Considerações Finais}

Esta pesquisa teve como objetivo identificar como a diversificação horizontal dos processos de impressão é utilizada em empresas gráficas da Região Metropolitana de Campinas-SP.

$\mathrm{O}$ estudo constatou que as gráficas pesquisadas disputam o mesmo mercado consumidor, e que as estratégias de diversificação utilizadas são semelhantes. Apesar das declarações de melhora nos resultados, tanto produtivos quanto econômicos, nenhum dirigente considerou a diversificação como um diferencial competitivo.

A diversificação dos processos de impressão não foi considerada como um diferencial competitivo, mas foi tida pelas empresas como essencial no sentido de atender a demanda, corroborando com os estudos de Coy (2018), Freire (2019), Caspary (2016), Kretzer (2015) e Vieira \& Araújo (2015).

A pesquisa demonstrou também que os processos de diversificação, observados nas empresas estudadas, apresentam diferenças específicas e individuais, com motivações estratégicas, mercadológicas e financeiras, mas não apresentam diferenças substanciais quando confrontadas com o referencial teórico, pois todas buscam a possibilidade de aumentar o faturamento e ampliar sua área de atuação por meio da estratégia de diversificação horizontal.

É interessante notar que os entrevistados afirmaram que os novos tipos de impressão ainda têm pouca oferta e maior demanda que o processo offset. Desse modo, conclui-se nessa pesquisa que muitas empresas diversificam seus processos de impressão por meio de terceirização. Assim, pode-se afirmar que a maioria das empresas gráficas diversificam seus produtos e serviços, mas nem todas diversificam seus processos de impressão.

Compreende-se também que as empresas ainda são dependentes do produto base para manutenção da atividade, mas reconhecem que nos novos produtos e serviços as margens de lucro são maiores. Além disso, vê-se nitidamente dois aspectos importantes mencionados na literatura: a aprendizagem e as relações entre os membros da organização (Mintzberg et al., 2000; Vallandro, 2016.

Em relação às dificuldades oriundas do processo de diversificação, os dados levantados nas empresas coincidem com o referencial teórico. Os principais desafios relatados foram falta de recursos financeiros, pouco conhecimento sobre os novos produtos, processos e dificuldade de encontrar mão de obra qualificada, de modo semelhante ao referencial apresentado (Penrose, 1979; Mintzberg et al., 2000; Vallandro, 2016; Silva et al., 2017; Smith \& Coy, 2018)

Considera-se que esses resultados são relevantes, além da academia, para as organizações gráficas, em geral. A ideia é que, a partir dos resultados apresentados, as empresas que diversificam ou pretendem diversificar seus processos de impressão possam entender quais os elementos que podem trazer melhores 
resultados e também quais as principais barreiras ou dificuldades que podem limitar a aplicação dessa estratégia, já que tais elementos podem influenciar diretamente nos resultados.

\section{Referências}

Abigraf Nacional - Números Da Indústria Gráfica Brasileira: Dados Econômicos Regionais www.abigraf.org.br - Janeiro/2016.

Adobor, H. Opening Up Strategy Formulation: Benefits, Risks, And Some Suggestions - Kelley School Of Business, Indiana University. Published By Elsevier Inc. All Rights Reserved https://doi.org/10.1016/j.bushor.2019.01.005 - No. Of Pages 112019.

Ansoff, H. I. Corporate Strategy: Na Analytic Approach To Business Policy For Growth And Expansion. Harmondswrth: Penguin Books, 1971.

Bardin, Laurence. Análise De Conteúdo. São Paulo: Edições 70, 2011.

Bardin, L. Análise De Conteúdo. São Paulo: Ed. Rev E Ampl. 2016.

Caspary, T. A Nova Lógica De Produção Da Indústria 4.0 - Publicação Do Sindicato Da Indústria Gráfica No Rio Grande Do Sul - Sindigraf-Rs - Revista Abigraf / Número 243 / Setembro / 2016.

Costa, H. T. As Preferências Da Mídia Impressa: Comunicação Destaque. Abigraf291: São Paulo, 14 Fev. 2018. Mensal. Disponível Em: http://www.anconsulting.com.br/pt-br/component/k2/item/126. Acesso Em: 23 Abr. 2018.

Dal Et Al. Desenvolvimento De Novos Serviços E Competitividade: Da Proposição De Valor À Cocriação De Valor Como Possível Fonte De Vantagem Competitiva. Revista De Administração Da Unimep, V. 15, N. 2, P. 1-25, 2017.

Flick, U. Introdução À Pesquisa Qualitativa (3a Ed., J. E. Costa, Trad.). São Paulo: Artmed. 2009.

Forte, E. C. N. Et Al. A Hermenêutica E O Software Atlas Ti: União Promissora - Texto \& Contexto Florianópolis, V. 26, N. $4 \quad$ E0350017, $2017 \quad-\quad$ Disponível Em http://www.scielo.php?script=sci_arttext\&lng=pt\&nrm=iso. Epub 17/Nov/2017.

Freire, C. Economic Diversification: A Model Of Structural Economic Dynamics And Endogenous Technological Change, Structural Change And Economic Dynamics https://doi.org/10.1016/j.strueco.2019.03.005 - 2019.

Grzebieluckas, C.; Marcon, R.; Alberton, A. A Estratégia De Diversificação E Performance: O Caso Das Companhias Abertas No Brasil• Ram, Rev. Adm. Mackenzie, V. 14, N. 2 • Issn 1518-6776• Issn 16786971 • São Paulo, Sp Mar. /Abr. 2013.

Justo, T. C. T. Impressão Digital: Tecnologia E Impressão De Dados Variados. 215 F. Dissertação (Mestrado) - Curso De Área De Concentração: Design E Arquitetura, Universidade De São Paulo Fauusp, São Paulo, 2015. 
Kretzer, J. A Diversificação Da Estrutura Produtiva No Brasil: Observações Preliminares - Revista De Economia Contemporânea (Journal Of Contemporary Economics) Issn 1980-5527 http://dx.doi.org/10.1590/198055271925 - 19(2): P. 280-306, 2015.

Lembe, F. V. Estratégias e Vantagens Competitivas Sustentáveis: Um estudo na Fábrica Água Mineral do Tchiowa - Dissertação. Departamento de Ciências Económicas, Empresariais e Tecnológicas Universidade Autônoma de Lisboa, março de 2018.

Martins, M. F. M. A influência do ambiente operacional na relação entre diversificação e desempenho: um estudo aplicado ao mercado de manufatura norte-americano. Dissertação Adm. MACKENZIE, U. P. São Paulo 2011.

Mintzberg, H.; Bruce, A; Joseph, L. Safári de Estratégia: um roteiro pela selva do planejamento estratégico, Porto Alegre: Bookman, 2000.

Penrose, E. T. The Theory of the Growth of the Firm. New York: John Wiley. 1959.

Penrose, E. T. A economia da diversificação. Rev. adm. empres., São Paulo, Acesso em 02 fev. 2019. http://dx.doi.org/10.1590/s0034-75901979000400001. v. 19, n. 4, p. 07-30 dez.1979.

Pessoa, L. Estratégias Inovadoras: Como fazer? Teoria e Prática. Lisboa: Editora, RH Lda. 2010.

Porter, M. E. Vantagem Competitiva; Criando e Substaining Desempenho Superior, The Free Press, New York, NY [Google Scholar] 1985.

Porter, M. E. “Qual é a estratégia?”, Harvard Business Review, Vol. 74 No. 6, pp. 61 - 78, 1996.

Rumelt, R. P. - Diversification strategy and profitability. Strategic Management Journal. v.3, p. 359-369, 1982.

Saracco, F.; Di Clemente, R.; Gabirelli, A.; Pietronero, L. (2015). From innovation to diversification: A simple competitive model. PLOS ONE, DOI: 10.1371/journal.pone.0140420. November 6, 2015.

Silva, P. G. S.; Araújo, A. G.; Damasceno, L. M. S.; Serralvo, F. A. - O processo da estratégia sob a visão dos decisores - Revista Capital Cientifico - Eletrônica (RCCe) - ISSN 2177-4153 - Vol. 15 n.3 julho/setembro 2017.

Silva, S. B. Estrutura de Capital e Diversificação de Negócios de Empresas Brasileiras. Tese Adm. MACKENZIE, U. P. São Paulo 2018.

Smith, G. C. C.; Coy, J. M. "A diversificação empresarial: Pode o desconto diversificação observado lançar luz sobre a escolha de gestão para diversificar ou re-foco? ", Revisão de Contabilidade e Finanças https://doi.org/10.1108/RAF-11-2016-0172 - Vol. 17 Emissão: 3, pp.405-424, 2018.

Soltanizadeh, S.; Rasid, S. Z. A.; Golshan, N. M.; Ismail. W. K. W. Business strategy, enterprise risk management and organizational performance, Management Research Review, https://doi.org/10.1108/ MRR-05-2015-0107. Vol. 39 Issue: 9, pp.1016-1033, 2016.

Teece, D. J. Towards an Economic Theory of the Multiproduct Firm. Journal of Economic Behavior \& Organization, 3, 39-62. 1982. 
Vallandro, L. F. J. Fatores determinantes da direção da estratégia de diversificação de grupos empresariais: teoria e evidências do Brasil. Tese (doutorado) Universidade do Vale do Rio dos Sinos, Programa de PósGraduação em Administração, 182 f. 2016.

Vieira, E. F.; Araújo, R. M. Agregação De Valor Aos Produtos E Serviços: Um Estudo Realizado Em Indústrias Gráficas. Revista Científica da Escola de Gestão e Negócios - Universidade Potiguar - ISSN 22368760 - Ano 4, no 1, jan. 2015.

YIN, R. K. Qualitative research from start to finish, 2 ed., Guilford, New York, NY. 2015.

\section{Sobre o Autor}

\section{MARCOS LEITE DE ARAUJO}

(iD) ORCID: https://orcid.org/0000-0003-3012-4410

Mestre em Administração pela Universidade Metodista de Piracicaba (UNIMEP); Pós-graduado em Gestão Estratégica em Negócios pela Universidade Mackenzie de Campinas, SP e; Graduado em Gestão de Serviços pela Faculdade de Tecnologia de Indaiatuba (FATEC).

Enviado em: 29 agosto. 2021.

Aprovado em: 15 fev. 2021. 